\title{
Principles and indicators of green living families in Thai context
}

\author{
Yuranun Tamkarn ${ }^{1 a}$, Suwithida Charungkaittikul ${ }^{1}$, and Kiatiwan Amatyakul ${ }^{1}$ \\ ${ }^{1}$ Chulalongkorn University, Bangkok, 10330, Thailand
}

\begin{abstract}
Green Living has been practiced in everyday life which is accepted worldwide. However, there is no concrete academic principles for Green Living. The understanding of Green Living is rather abstract. This study focuses on the academic principles and indicators of the Green Living Families in Thailand. The results from the studies will be used for further research. This qualitative study aims at proposing the principles and indicators of the Green Living Families in the Thai context. The research methodologies include the analysis and synthesis of various documents both from Thailand and foreign countries, interviews and observation of five Green Living Families. The results show that the principles consist of 1) production for one's own consumption within the family 2) economical use of resources and 3) sharing with others and the society. The essential indicators comprise of 1) Knowledge, 2) Practice, and 3) Attitude on Green Living.
\end{abstract}

Keywords: green living; green living families in Thailand, principles of green living

\section{Introduction}

This paper presents part of the Ph.D. thesis entitled 'Development of a Participatory Learning Process Based on Green Living to Enhance Family Well-being'. This research study aims at 1) analyzing primary data on Green Living Families and learning contents based on Green Living principles for the well-being of Green Living Families from good study cases; and 2) to develop participatory learning process based on Green Living to enhance family well-being. This research focuses on means to enhance well-being within families. Present-day Thai families, particularly those in the capital, encounter the lack of well-being in all aspects; namely, physically, mentally, socially and intellectually [2, 4, 7, 9,8]. Previous research studies in Thailand explore various means of enhancing well-being, both at the individual and community levels [6], physically, mentally, socially and intellectually; however, none on well-being enhancement particularly for families even though family is a very important social institution. Problems and solutions should start at

\footnotetext{
${ }^{a}$ Corresponding author: sano717@hotmail.com
} 
the family level. This study is interested in an alternative means to enhance well-being of families holistically: physically, mentally, socially and intellectually. That is Green Living, which is an everyday practice, emphasizing on self-reliance and sodality with the environment which positively affects the participants' mental health and relationship within the family as well as the world $[3,1]$.
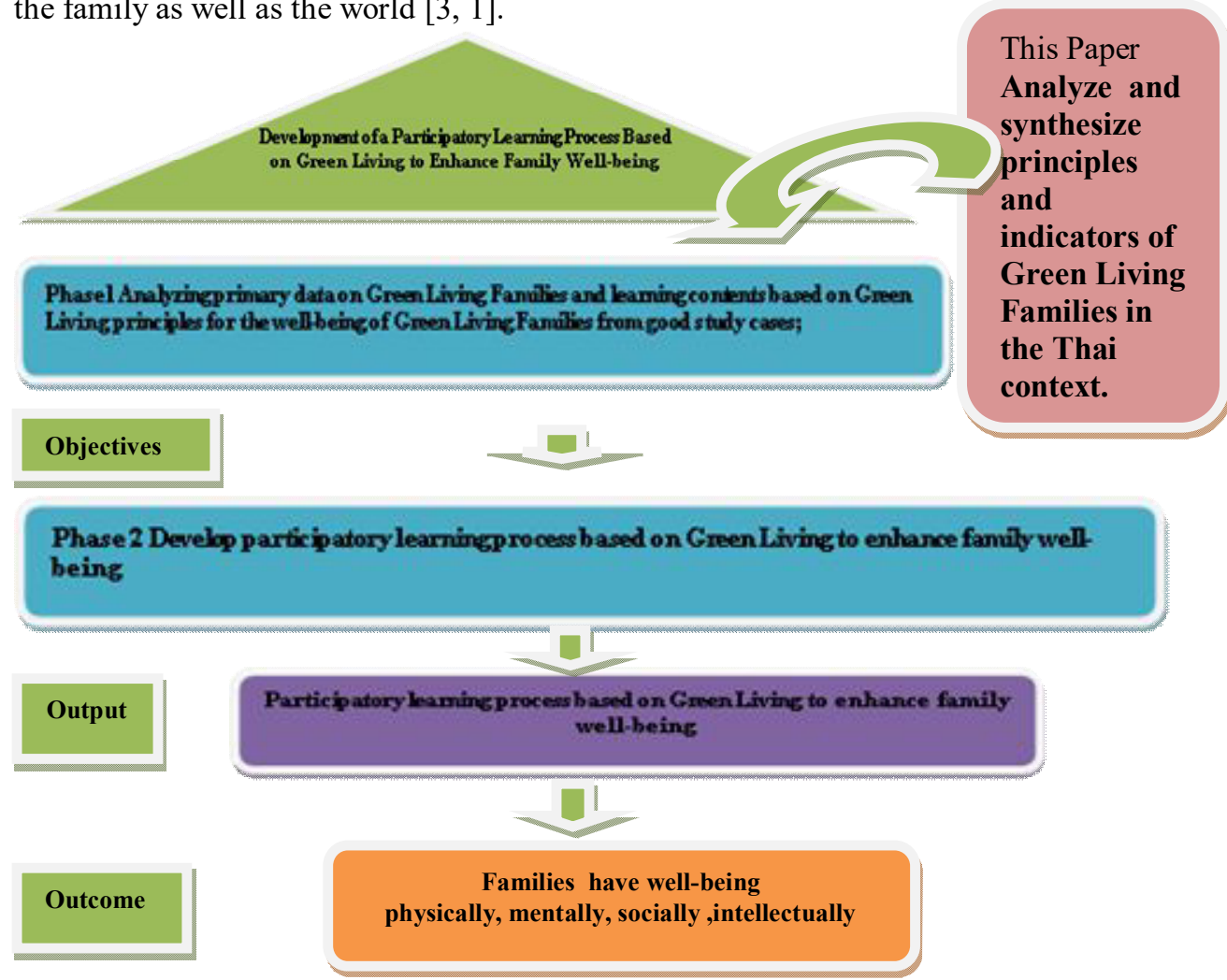

Fig 1. Overview of Ph.D. thesis

\section{Rationale}

Green Living is one of the concepts that have caught people's attention. From the review of document and public media, the understanding of Green Living can be defined as one's life on the basis of making a decision by considering the effect to the environment and lifestyle, in which one consumes or avails of only necessary things from world's resources.

Green Living is a rather abstract preference. Although there has been various groupings of Green Living members, they are still exclusive. Moreover, there is no concrete academic principle for Green Living. The understanding of Green Living is rather abstract. Therefore, there is no principle or concept of Green Living that can be used as a reference for academic study.

Moisander and Pesonen [5] indicate that research studies on Green-Living address the practice, product selection and way of life, but there has been no study indicating their means, processes and origins. This study focuses on the academic principles and indicators of the Green Living Families in Thailand and indicators of the Green Living Families in the Thai context. 


\section{Objectives}

3.1 To analyze and synthesize academic principles of Green Living Families in the Thai context.

3.2 To analyze and synthesize indicators of Green Living Families in the Thai context.

\section{Methodology}

The researchers used a qualitative study to construct principles and indicators of Green Living and/or Green Living Families or Green Families by analyzing and synthesizing the content on Green Living from documents, consisting of internet documentary articles from Thai and foreign websites, journal articles, newspaper interview articles, pocket books and research articles featuring the topic of Green Living. Among these, 30 were chosen, along with a study of data of Green Living Families or Green Family, excerpts from presentations at Green Living fairs where group members gather, and in-depth interviews and observation of members from two of the Green Living Families.

\section{Results}

From the document synthesis and the interviews with the members of some Green Living Families, the researchers concluded on the Green Living Principles and indicators for Green Living Families to be used in the next stage of the study. Regarding the Green Living Principles, the researchers found the common ground of the practice or activities in various families, which can be summarized into three points:

\subsection{Principles of the Green Living Family}

\subsubsection{Production for one's own consumption in the family}

The family produces goods for the family's own uses regularly, but it does not mean that nothing is bought into the house. The documents and interviews indicated that Green Living Families make all-purpose washing agents such as washing-up liquid and toilet cleaner; toiletries such as soap, shampoo, body lotion, coconut oil; agricultural products such as fertilizer from manure and fermented from scraps of left-over fruits and vegetables. What was found in almost every family is growing vegetables for their own consumption.

\subsubsection{Economical Use of Resources}

This means consumption, living and eating in moderation and without luxury, such as buying clothes without observing fashion, use of a small car or using public transports instead of private cars, using reusable containers instead of plastic containers, using plastic bottles to make plant pots, and 3Rs activities. These are the most common and obvious examples of this.

\subsubsection{Sharing with others and society}


Green Living Families share homemade products, knowledge and time with others, give advice on compliance activities, train people how to grow organic vegetables, deliver vegetables to members and participate in volunteer activities to benefit the public.

\subsection{Indicators of the Green Living Families}

The indicators of Green Living Families can be categorized into Knowledge, Practice and Attitude. The researchers synthesized and concluded from the afore-mentioned Green Living Principles, which is a result of document studies and interviews with those observing Green Living. Preliminarily,

1. The Knowledge indicators of Green Families are knowledge on organic vegetable planting, waste separation, making homemade consumer products, cooking, organic agriculture, using herbal medicine, using green-labeled and energy-saving products, locating clean food and handmade product markets, and keeping family's account.

2. The Practice of Green Families are planting fruits and vegetables for one's own consumption, waste separation prior to disposal, reusing or recycling, making organic fertilizer for home-grown fruits and vegetables, making all-purpose cleaners, using green-labeled products, buying food directly from producers, cooking at home, using herbal medicine to treat mild illness, keeping accounts, participating in group's or community's activities, participating in volunteer activities, sharing fruits and vegetables grown at home with neighbours or colleagues, teaching or advising others on certain topics such as planting, speaking to children or those interested, using media in publicizing knowledge, concepts and activities that the family does, using washable containers, using small cars, cycling and using public transports.

3. The Attitudes of Green Families include self-confidence, generosity, sensibility, self-sufficient lifestyle, strength and endurance, inspiration, optimism, love for knowledge, appreciating others, understanding differences and respecting others.

\section{Conclusion}

This principles and indicators of the Green Living Families will benefit those interested in Green Living and in adoption of Green Living issues in the future. However, given the synthesis and analysis time, the information is only to be used for studying Green Families in the research 'Development of a Participatory Learning Process Based on Green Living to Enhance Family Well-being'. The research is expected to have data to confirm this or add to it.

\section{References}

1. Apichit P., Urban Green Living: Body, Mind and Soul (Green Guide Book Vol.2), Bangkok: Suan Nguen Mee Ma, (2009).

2. Bundhamcharoen K., Inner Health in Thai Health 2011: HIA Public Policy Development Strategies for Life and Health, 10-11. Nakhon Pathom: Institution for Population and Social Research, Mahidol University, (2011).

3. Hongsang S., Sustainable Tourism Community. Bangkok: Suan Nguen Mee Ma, (2011). 
4. Kanchanachitra $\mathrm{C}$ et al., Uncontrolled Exaggerated Health Advertisements in Thai Health 2011: HIA Public Policy Development Strategies for Life and Health, 72-75. Nakhon Pathom: Institution for Population and Social Research, Mahidol University, (2011).

5. Moisander J and Pesonen S., Narratives of sustainable ways of living: constructing the self and the other as a green consumer. Journal of Management Designs (40) 2002: 329 - 342, (2002).

6. Tantaviwong A, ed., Paths to Happiness. Bangkok: Graduate School, Chulalongkorn University, (2011).

7. Tantipiwattanakasul P., Mental Health in Thai Health 2011: HIA Public Policy Development Strategies for Life and Health, 12-13. Nakhon Pathom: Institution for Population and Social Research, Mahidol University, (2011).

8. Thai Health Project. Thai Health in the Past 10 Years., Thai Health 2013: Thailand Reformation Power Structure Reformation for the People, 6-7. Nakhon Pathom: Institution for Population and Social Research, Mahidol University, (2013).

9. Thayansin S., Family Relationship in Thai Health 2011: HIA Public Policy Development Strategies for Life and Health, 22-23. Nakhon Pathom: Institution for Population and Social Research, Mahidol University, (2011). 